\title{
The Action of Bromine on Podophyllotoxin and Picropodophyllin
}

\author{
HELMER KOFOD and CHR. JøRGENSEN
}

Danmarks farmaceutiske Hфjskole, organisk-kemisk Laboratorium, Kфbenhavn, Danmark

\begin{abstract}
The preparation of a new monobromo-derivative of podophyllotoxin was reported in a recent short communication. The position of the bromine atom has now been established by oxydative degradation with permanganate. The isolation of 2-bromo-3,4,5-trimethoxybenzoic acid proves that the structure of "bromopodophyllotoxin" is 1-hydroxy-4 (2-bromo-3,4,5-trimethoxyphenyl)-6,7-methylenedioxy2-hydroxymethyl-1,2,3,4-tetrahydro-naphthoic acid-(3) lactone (Fig. 4).

Hydrogenation with Raney-nickel catalyst leads to picropodophyllin. Bromopodophyllotoxin forms a crystalline acetyl derivative.

The epimeric compound, bromo-picropodophyllin, has been prepared both by base-catalyzed epimerization of bromopodophyllotoxin and by bromination of picropodophyllin.
\end{abstract}

$\mathrm{B}^{y}$ the action of bromine in a slight excess on a paste of powdered podoB phyllotoxin (Fig. 1, I) and glacial acetic acid Dunstan and Henry ${ }^{1}$ obtained a bromo-derivative, which they described as colourless crystals melting above $250^{\circ} \mathrm{C}$ and containing $20.9 \% \mathrm{Br}$. The empirical formula $\mathrm{C}_{15} \mathrm{H}_{14} \mathrm{O}_{6} \mathrm{Br}$ (calc. $21.6 \% \mathrm{Br}$ ) was proposed, podophyllotoxin itself being erroneously ascribed the formula $\mathrm{C}_{15} \mathrm{H}_{14} \mathrm{O}_{6}$.

By a similar procedure picropodophyllin (II) yielded a reaction product, which failed to crystallize, except from ethanol, and the dissolution in this medium was accompanied by liberation of free bromine.

Fractional precipitation with ether and light petroleum of a product, which had previously been recrystallized from ethanol, yielded a substance melting at $138^{\circ} \mathrm{C}$ and containing $18.85 \% \mathrm{Br}$. The authors held the view that it was an isomeride of bromo-podophyllotoxin.

A different bromo-derivative of podophyllotoxin was obtained by Hartwell and Schrecker ${ }^{2}$ by treatment of podophyllotoxin with phosphorus tribromide or thionyl bromide, the hydroxy-group being thereby replaced by a bromine atom. This "podophyllotoxin bromide" was reported to melt at $157.5-159^{\circ} \mathrm{C}$, to give an immediate precipitate of silver bromide with alcoholic silver nitrate and to be rapidly hydrolyzed by water.

Acta Chem. Scand. 9 (1955) No. 8 


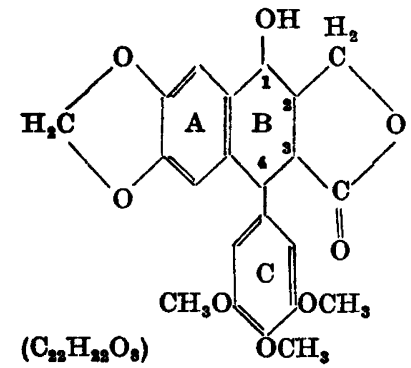

I Podohyllotoxin (PT) trans-1:2-trans-2:3-cis-3:4 II Picropodophyllin (PP) trans-1:2-cis-2:3-trans-3:4

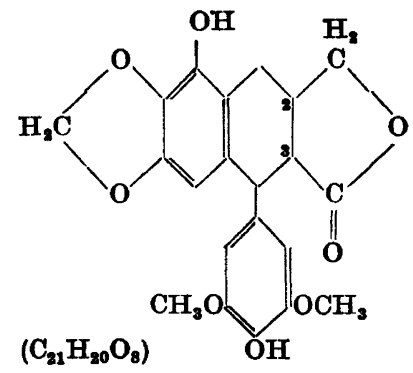

III $\alpha$-Peltatin trans-2:3-cis-3:4

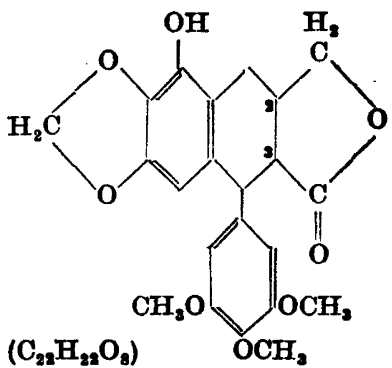

IV $\beta$-Peltatin trans-2:3-cis-3:4

Fig. 1.

Further allusion to the subject is found in a paper by Hartwell and Detty ${ }^{8}$, in which it is stated that podophyllotoxin and the peltatins (III and IV) are unreactive in the usual bromine test for unsaturation and that the methyl ethers of the peltatins substitute bromine with evolution of hydrogen bromide.

In a recent short communication 5 we have reported that podophyllotoxin dissolved in chloroform and shaken with an aqueous bromine solution at room temperature virtually consumes approximately 2 equivalents of bromine per molecule. A solvate of the composition $\mathrm{C}_{22} \mathrm{H}_{22} \mathrm{O}_{8}, \frac{1}{2} \mathrm{C}_{6} \mathrm{H}_{6}, \mathrm{H}_{2} \mathrm{O}$ was used for these quantitative experiments.

The experimental equivalent weights varied with the excess of bromine and with the reaction time in a poorly reproducible manner, and the method proved inadequate for quantitative determination of podophyllotoxin. Under certain conditions, specified in the experimental section, equivalent weights in the neighbourhood of 235 were obtained. The calculated value is 235.5 on the assumption that 2 equivalents of bromine are consumed, one of which enters the podophyllotoxin molecule, the other one forming hydrogen bromide. When the reaction time was extended and/or when a larger excess of bromine was employed, considerably lower equivalent weights were obtained, probably indicating the substitution of a second hydrogen atom in the podophyllotoxin molecule.

Under the conditions leading to monosubstitution of podophyllotoxin picropodophyllin also gave equivalent weights fairly close to the value for monosubstitution. In both cases we have succeeded in isolating the monobromoderivative.

Monobromo-podophyllotoxin was described in a preliminary communication $^{5}$ and the data are given in the experimental section in the present paper. Although one of its melting points $\left(155^{\circ} \mathrm{C}\right)$ is close to the melting point of Hartwell and Schrecker's podophyllotoxin bromide $\left(157.5-159^{\circ} \mathrm{C}\right)^{2}$, there is clear evidence that our product is a different compound. Contrary to podophyllotoxin bromide our bromo-derivative gave no precipitate of silver halide with silver nitrate even when heated, and the bromine was not split off in boiling alcoholic sodium hydroxide. It is obvious, therefore, that 
Fig. 2. Paper chromatogram, formamidepaper/benzene, $25.0^{\circ}$; general technique vide Ref. ${ }^{16}$ spray-reagent antimony pentachloride.

1. Standard podophyllin, showing reference spots of a-peltatin, (a), podophyllotoxin $(P T)$ and $\beta$-peltatin $(\beta)$.

3. Authentic podophyllotoxin.

5. Product obtained on hydrogenolysis of bromo-podophyllotoxin.

6. Authentic picropodophyllin.

7. As No. 1.

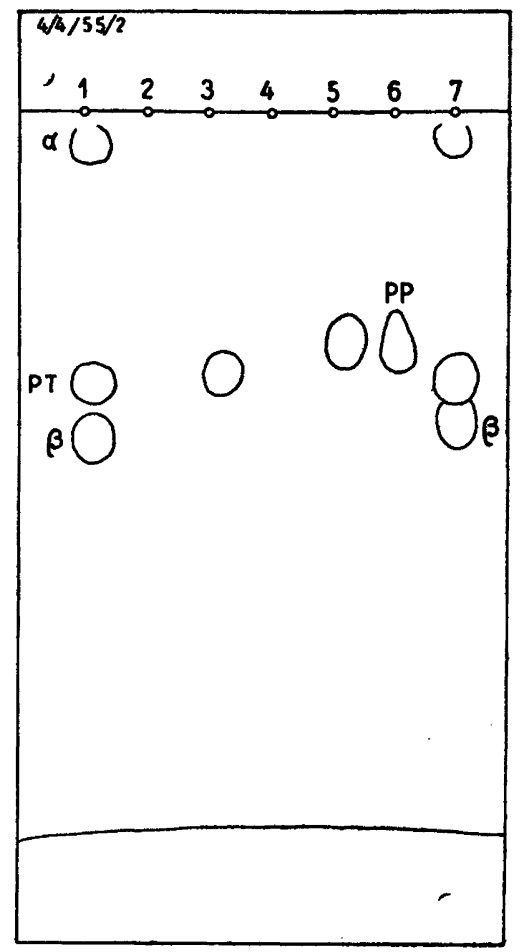

the bromine atom is linked to an aromatic ring. That the hydroxy-group of podophyllotoxin (I) is intact in our derivative is compatible with the elementary analysis and unequivocally proved by the existence of an acetyl derivative and by the observation that the bromo-derivative may be hydrogenated with Raney-Ni catalyst to picropodophyllin, the bromine-atom being thereby removed and the resulting podophyllotoxin epimerized in the alkaline solution. The identity of the hydrogenation product with authentic picropodophyllin was proved by melting point and paper chromatography, Fig 2.

The exact position of the bromine atom in monobromo-podophyllotoxin remains to be discussed. According to the above observations the bromine atom may have entered either ring $\mathrm{A}$ or ring $\mathrm{C}(\mathrm{I})$. It was thought that an oxidative degradation of the molecule would distinguish between these possibilities. Permanganate oxidation of bromo-podophyllotoxin may be expected to proceed as indicated for the parent compound in Fig. 3, bromoderivatives of (V), (VI) or (VII) being formed, depending upon the position of the bromine atom and the experimental conditions. By exhaustive permanganate oxidation of podophyllotoxin at $100^{\circ}$ in weakly alkaline solution Späth et al. ${ }^{6}$ obtained trimethoxybenzoic acid (VI) in good yield, whereas the rings $\mathrm{A}, \mathrm{B}$ and $\mathrm{D}$ were completely broken down to oxalic acid. Shortly afterwards similar results were reported by Borsche and Niemann ?. By an

Acta Chem. Scand. 9 (1955) No. 8 
Fig. 3. Oxidative degradation of podophyllotoxin $:-10$

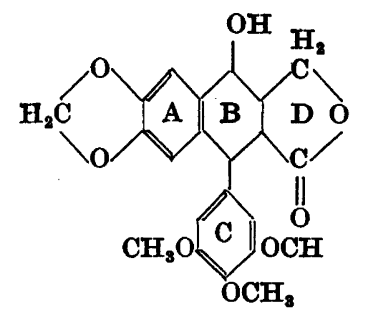<smiles>CCCCCCCC</smiles><smiles>CCOC(=O)c1cc(OC)c(OC)cc1C(=O)O</smiles>

I Podophyllotoxin<smiles>COc1ccc(OC)c(C(=O)O)c1</smiles>

VI 3,4,5-Trimethoxybenzoic acid

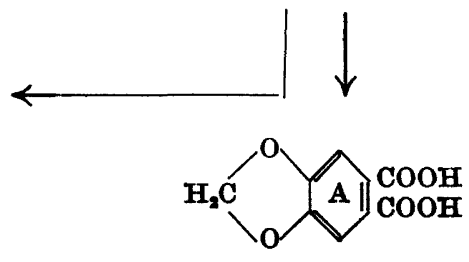

VII Hydrastic acid

Fig. 4. Bromo-podophyllotoxin.

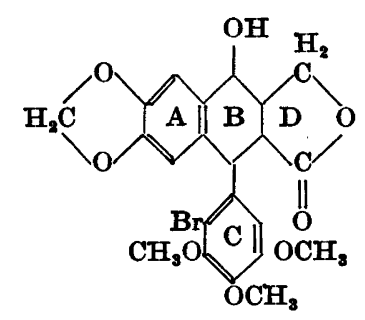

oxidation carried out under milder conditions $\left(50^{\circ} \mathrm{C}\right)$ Späth et al. ${ }^{8}$ later obtained the intermediate keto-acid (V), the structure of which they proved by synthesis. It is of no consequence in this connection that their starting material was picropodophyllin, since this compound differs from podophyllotoxin only in the configuration of ring B. Further oxidative degradation of (V) would be expected to give a mixture of (VI) and (VII). Hydrastic acid (VII) was isolated in a very small quantity from permanganate oxidation of podophyllotoxin at $60-70^{\circ} \mathrm{C}$ by Späth et al. ${ }^{9}$.

Degradation products closely analogous to (V), (VI) and (VII) have been isolated from a permanganate oxidation of the peltatins and their ethers by Sohrecker and Hartwell ${ }^{10}$, cf. $^{3}$. The general scheme of reactions in Fig. 3 is therefore well established.

On oxidation of bromopodophyllotoxin with excess of permanganate at $100^{\circ} \mathrm{C}$ we have obtained a crystalline substance, which proved to be monobromo-trimethoxybenzoic acid (monobromo-VI). This finding settles the question as to the position of the bromine atom; it has substituted one of 
Fig. 5. Ultraviolet absorption curves (96\% ethanol). 3,4,5-trimethoxybenzoic acid. -.. 2-bromo-3,4,5-trimethoxybenzoic acid. 0 Degradation product from bromopodophyllotoxin.

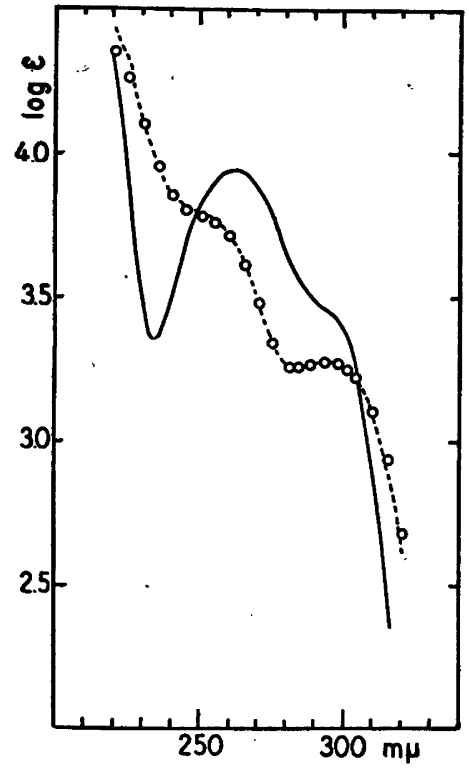

the remaining hydrogen atoms at ring C (Fig. 4) and has not entered ring A, as we tentatively suggested in our preliminary communication ${ }^{5}$.

The identity of the degradation product was established in the following way. Its melting point was $151-152^{\circ}$ (lit. $151-152^{\circ}$, Ref. ${ }^{11},{ }^{12}$ ) and it did not depress the melting point of an authentic sample, prepared synthetically. Its ultraviolet absorption curve was identical with the curve of the synthetic bromo-derivative but distinctly different from that of the parent compound, trimethoxybenzoic acid itself, Fig. 5 .

From an oxidation carried out under milder conditions $\left(55^{\circ}\right)$ two degradation products were obtained. One of these, which did not contain bromine, came out in a quantity too small for complete purification. It has not been definitely identified but is believed to be hydrastic acid. Its melting point was $175^{\circ} \mathrm{C}$; hydrastic acid is reported to melt at $173-187^{\circ}$ or higher, depending upon the rate of heating, more or less anhydride being formed during the melting process ${ }^{13}$.

The second product isolated from the "mild degradation procedure", provisionally named 19/10/54/I, analyzed as bromopodophyllotoxin, but had a much higher melting point, $225-229^{\circ} \mathrm{C}$. It would be a reasonable guess therefore, that it consisted of bromo-picropodophyllin, the epimer of the non-oxidized starting material, the formation of which could be anticipated, since the oxidation mixture becomes weakly alkaline during the process. For the purpose of comparison authentic bromo-picropodophyllin was therefore prepared both by bromination of picropodophyllin and by base-catalyzed, inversion of bromo-podophyllotoxin. The latter two compounds proved to be identical with respect to optical rotation and the $R_{F}$-value on paperchromatograms, Fig. 6. Their ultra-violet absorption curves (Fig. 7, - - -

Acta Chem. Scand. 9 (1955) No. 8 


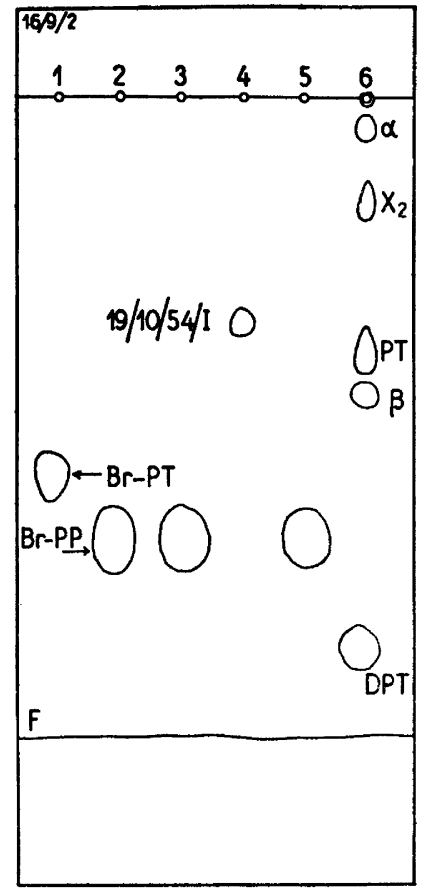

Fig. 6. Paper chromatogram, formamidepaper/benzene, $\quad 25.0^{\circ} \mathrm{C} . \quad$ Spray-reagent antimony pentachloride (general technique vide Ref.. ${ }^{16}$ )

1. Bromopodophyllotoxin (Br-PT) by bromination of podophyllotoxin.

2. Bromo-picropodophyllin (Br-PP) by inversion of bromopodophyllotoxin.

3. Bromo-picropodophyllin by bromination of picropodophyllin.

4. Substance 19/10/54/I isolated from degradation of bromopodophyllotoxin.

5. As 2.

6. Standard podophyllin, showing reference spots of a-peltatin (a) podophyllotoxin $(P T), \beta$-peltatin $(\beta)$ and desoxy-podophyllotoxin (DPT).

and -) showed qualitative agreement. The product obtained by bromination is probably not quite as pure as that prepared by inversion. Unfortunately they both failed to crystallize, a comparison by melting points thus being prevented.

From the ultraviolet absorption curve of the substance 19/10/54/I (Fig. 7 , O) it can only be inferred that it is closely related to bromo-picropodophyllin or bromo-podophyllotoxin, the curves of which are almost identical. The available quantity was insufficient for measurement of the optical rotation. Paper-chromatography gave the surprising result that the substance had a considerably lower $R_{F}$-value than the two authentic specimens of bromo-picropodophyllin. Fig. 6, No. 4, is representative of a large number of chromatograms, which all showed the same relative location, far above the spots of bromo-podophyllotoxin and bromo-picropodophyllin. This also implies that the substance cannot be merely a new crystal modification of bromo-podophyllotoxin. The possibility that the mild permanganate oxidation had caused a dehydrogenation at ring $B$ is ruled out, since the resulting compound, bromo-dehydropodophyllotoxin, would in all probability have an ultraviolet absorption curve similar to that of dehydropodophyllotoxin (Fig. 8, cf. Ref. ${ }^{15}$ ) and this is seen to be entirely different from the curve of the substance in question (Fig. 7, O). The substance 19/10/54/I may possibly have the structure indicated in Fig. 9; the parent compound podophyllotoxone (and picropodophyllone, respectively) has recently been obtained by Gensler 
Fig. 7. Ultraviolet absorption curves (96\% ethanol). - - bromopodophyllotoxin. bromo-picropodophyllin, by bromination of picropodophyllin. bromo-picropodophyllin, by inversion of bromopodophyllotoxin. O Substance 19/10/54/I isolated from degradation of bromopodophyllotoxin.

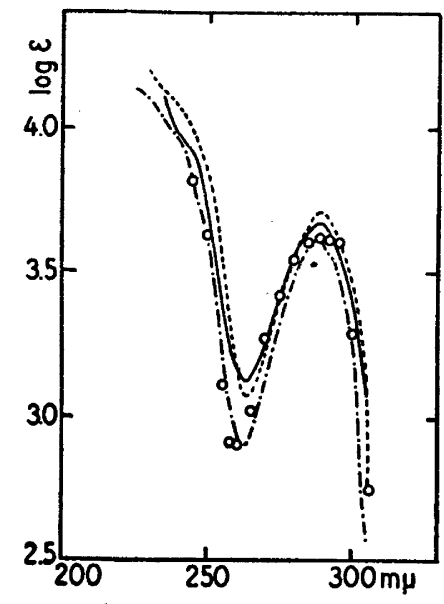

and Johnson 18 by oxidation of podophyllotoxin and picropodophyllin, respectively, with freshly prepared manganese dioxide, i.e. under conditions very similar to ours. The analytical figures for bromo-podophyllotoxone (Calc. for $\mathrm{C}_{22} \mathrm{H}_{19} \mathrm{O}_{8} \mathrm{Br}$ : C 53.8; $\mathrm{H} 3.9 ; \mathrm{Br} 16.3 ; 30 \mathrm{CH}_{3} 18.9$ ) fit fairly well with the experimental data. The ketonic structure would furthermore account for the anomalous location on paper chromatograms, and the ultraviolet absorption curve of substance $19 / 10 / 54 / \mathrm{I}$ has certain features in common with those

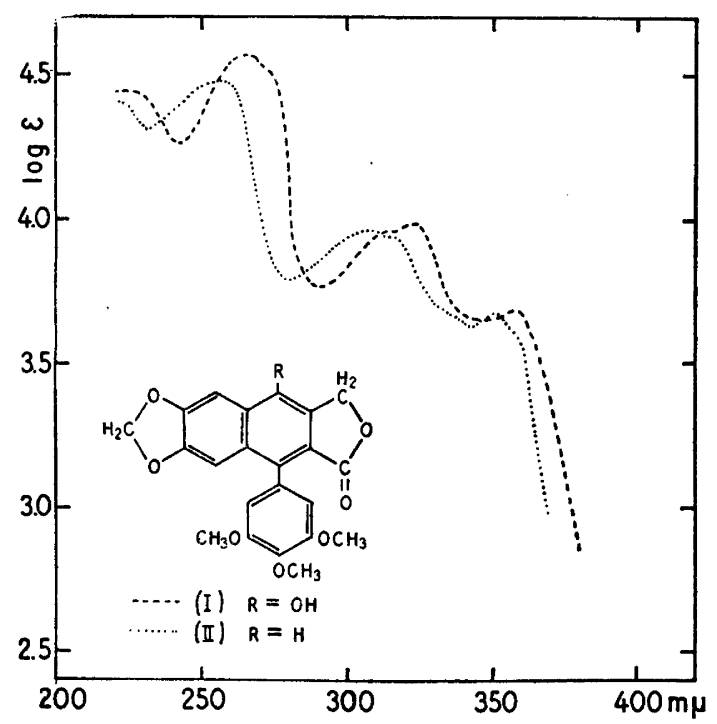

Fig. 8. Ultraviolet absorption curves (96 \% ethanol). --- dehydropodophyllotoxin ${ }^{15}$ .... dehydroanhydro-picropodophyllin.

Acta Chem. Scand. 9 (1955) No. 8 
reported for podophyllotoxone and picropodophyllone ${ }^{18}$. Further experiments in progress are hoped to produce conclusive evidence.

Finally it should be mentioned that we have not during our work isolated any substance corresponding to Dunstan and Henry's high-melting bromoderivative, to which we referred at the outset.<smiles>COc1cc2c(cc1OC)C(c1ccccc1)C1C(=O)OC[C@H]1C2=O</smiles>

Fig. 9. Bromo-podophyllotoxone, bromo-picropodophyllone.

\section{EXPERIMENTAL}

All melting points are corrected and have been determined with the hot-stage microscope essentially according to Kofler.

Podophyllotoxin and picropodophyllin. The preparation and characterization were as reported in a previous communication ${ }^{16} \mathrm{cf} .{ }^{17}$. Podophyllotoxin was a solvated product, analyzing as $\mathrm{C}_{22} \mathrm{H}_{22} \mathrm{O}_{8}, \mathrm{H}_{2} \mathrm{O}, \frac{1}{2} \mathrm{C}_{6} \mathrm{H}_{6}$ (mol.wt. 471), whereas picropodophyllin was unsolvated $\mathrm{C}_{22} \mathrm{H}_{22} \mathrm{O}_{8}$ (mol.wt. 414).

Bromination procedure. About $0.4 \mathrm{~g}$ of the substance was dissolved in $25 \mathrm{ml}$ of chloroform in a $100 \mathrm{ml}$ conical flask, provided with a ground glass stopper. $25.00 \mathrm{ml}$ of $0.1 \mathrm{~N}$ potassium bromate (2.5 milliequivalents bromine), $1.0 \mathrm{~g}$ of potassium bromide and 10 $\mathrm{ml}$ of $4 \mathrm{~N}$ sulphuric acid were added and the closed flask was allowed to stand in the dark for 15 minutes with frequent agitation. Then $5 \mathrm{ml}$ of potassium iodide solution (10\%) was added and the contents of the flask vigorously shaken. Upon standing for 5 minutes in the dark the reaction mixture was titrated with $0.1 \mathrm{~N}$ sodium thiosulphate, $5 \mathrm{ml} 1 \%$ starch solution being added towards the end of the titration.

With this standard procedure podophyllotoxin gave equivalent weights ranging from 220 to 238 , calculated 235.5 for monosubstitution. With a larger excess of bromine and/or extended reaction time somewhat lower equivalent weights were obtained. Picropodophyllin similarly gave equivalent weights in the region 200 to 230 , calculated 207 for monosubstitution.

The isolation of the bromination-products is described below.

Bromopodophyllotoxin. Five batches of bromination mixture prepared and titrated as above from a total of $2.0 \mathrm{~g}$ podophyllotoxin were used for the isolation of bromopodophyllotoxin. Every single batch showed a bromine consumption corresponding to monosubstitution. The separated aqueous layers were washed with chloroform, which was then added to the original chloroform layers. The combined chloroform volumes were washed with water, dried with anhydrous sodium sulphate and evaporated to dryness in vacuo. The residue was recrystallized from benzene and dried at $50^{\circ} \mathrm{C}$. Yield $1.6 \mathrm{~g}$ of colourless needles, melting partly at $155^{\circ}$ and partly at $183^{\circ} \mathrm{C}$. Subsequent drying to constant weight at $130^{\circ}$ and $0.01 \mathrm{~mm} \mathrm{Hg}$ gave a loss of weight amounting to $10.0 \%$ indicating that the substance was a solvate. The melting point $155^{\circ}$ is most probably that of the solvate and is not due to a specific crystal modification of the unsolvated substance as tentatively suggested in the prodromal communication. ${ }^{b}$ The melting point of the vacuum-dried sample was $182-183^{\circ} \mathrm{C}$, and it analyzed as monobromopodophyllotoxin (Found: $\mathrm{C}$ 53.6, 53.8; $\mathrm{H} \mathrm{4.4,4.5;} \mathrm{Br} 16.3,16.7 ; 3 \mathrm{OCH}_{3}$ 18.7. Calc. for $\mathrm{C}_{22} \mathrm{H}_{21} \mathrm{O}_{8} \mathrm{Br}$. (493.3): C 53.5; H 4.3; $\left.\mathrm{Br} 16.2 ; 3 \mathrm{OCH}_{3} 18.9\right)$. $[\alpha]_{\mathrm{D}}^{20}=-92^{\circ}$ (c 1.0, chloroform); $[\alpha]_{D}^{20}=-73^{\circ}$ (c 0.90 , ethanol). 
The substance gave no precipitate with alcoholic silver nitrate even on heating, and alcoholic sodium hydroxide boiled with bromopodophyllotoxin gave a negative test for bromide ion.

Acetyl-bromopodophyllotoxin. A mixture of $0.20 \mathrm{~g}$ of bromopodophyllotoxin and $5 \mathrm{ml}$ of acetic anhydride was refluxed for two hours. Excess of the reagent was decomposed at room temperature with $10 \mathrm{ml}$ of water. The isolated solid was recrystallized from benzene and dried to constant weight at $120^{\circ} \mathrm{C}$ and $0.01 \mathrm{~mm} \mathrm{Hg}(18 \mathrm{~h})$. Colourless needles melting at $217-221^{\circ} \mathrm{C}$ (Found: $\mathrm{C} \mathrm{53.7;} \mathrm{H} \mathrm{4.6;} \mathrm{Br}\left(16.0\right.$ ); $3 \mathrm{OCH}_{3}$ 17.9. Calc. for $\mathrm{C}_{24} \mathrm{H}_{23} \mathrm{O}, \mathrm{Br}$ (535.3): $\mathrm{C} 53.8 ; \mathrm{H} 4.3 ; \mathrm{Br} 14.9 ; 3 \mathrm{OCH}_{2}$ 17.4). [a] ${ }_{\mathrm{D}}^{20}=-93^{\circ}$ (cf. 0.88; chloroform).

Bromopicropodophyllin (by bromination of picropodophyllin). By bromination and isolation as described for bromopodophyllotoxin above, an almost colourless amorphous solid was obtained. Attempts to bring it into the crystalline state proved unsuccesful. A sample, which had been dried to constant weight at $100^{\circ} \mathrm{C}$ and $0.01 \mathrm{~mm} \mathrm{Hg}$, analyzed as unsolvated bromopicropodophyllin (Found: $\mathrm{C} 53.6 ; \mathrm{H} 4.4 ; \mathrm{Br} 15.9$; Calc. for $\mathrm{C}_{22} \mathrm{H}_{21} \mathrm{O}_{2} \mathrm{Br}$ (493.3): C 53.5; $\mathrm{H} \mathrm{4.3;} \mathrm{Br} 16.2 ; 3 \mathrm{OCH}_{3}$ 18.9). Paperchromatographic examination (Fig. 6) and the ultraviolet absorption spectrum (Fig. 7) as well as the optical rotation, $[\alpha]_{\mathrm{D}}^{20}=-17.5^{\circ}(\mathrm{c}=1.09$; chloroform), strongly suggest that the substance is identical with bromopicropodophyllin, obtained by inversion of bromopodophyllotoxin (vide infra). The amorphous substance failed to give a crystalline acetyl derivative.

Bromopicropodophyllin (by inversion of bromopodophyllotoxin).

A solution of $1.0 \mathrm{~g}$ of bromopodophyllotoxin and $0.2 \mathrm{~g}$ of anhydrous sodium acetate in $20 \mathrm{ml}$ of $99 \%$ ethanol was refluxed for 18 hours. The reaction mixture was allowed to cool to room temperature, $40 \mathrm{ml}$ of water was added, and the solution was extracted with $2 \times 50 \mathrm{ml}$ of chloroform. The combined chloroform layers were dried with anhydrous sodium sulphate and evaporated to dryness in vacuo. The almost colourless residue did not crystallize and showed an undefined melting point. $[\alpha]_{D}^{20}=16.5^{\circ}$ (c 1.03 ; chloroform).

The ultraviolet absorption spectrum (Fig. 7) shows the essential features common to bromopodophyllotoxin and the bromination product of picropodophyllin. A paperchromatographic examination (Fig. 6) clearly indicates identity with the latter and non-identity with the former compound.

Hydrogenation of bromopodophyllotoxin. 100 milligrams of bromopodophyllotoxin were dissolved in $5 \mathrm{ml}$ of $99 \%$ ethanol, $0.1 \mathrm{~g}$ of Raney-nickel catalyst and $5 \mathrm{ml}$ of $2 \mathrm{~N}$ sodium hydroxide were added and the mixture was refluxed on a steam bath for 20 minutes. The solution was diluted with $10 \mathrm{ml}$ of water, acidified with sulphuric acid and shaken out with two times $20 \mathrm{ml}$ chloroform. The combined chloroform phases were dried with anhydrous sodium sulphate and evaporated to dryness in vacuo. The residue was recrystallized from $99 \%$ ethanol and yielded a few milligrams of colourless needles, m.p. $223-224^{\circ} \mathrm{C}$. The sample did not depress the melting point of an authentic specimen of picropodophyllin and the identity was further evidenced by paper-chromatographic comparison (Fig. 2).

Permanganate oxidation of bromopodophyllotoxin at $100^{\circ} \mathrm{C} .1 .0 \mathrm{~g}$ bromopodophyllotoxin was dissolved in $20 \mathrm{ml}$ of $1 N$ sodium hydroxide and $10 \mathrm{ml}$ of aceton. The solution was placed in a $400 \mathrm{ml}$ beaker, fitted with a mechanical stirring device, and heated on the steam bath. A $4 \%$ potassium permanganate solution was added by $5 \mathrm{ml}$ batches with continuous stirring, no batch being added until the preceding one was decolourized. After addition of $150 \mathrm{ml}$ of permanganate solution the aceton was distilled off and more permanganate was added until the colour became persistent (additional $100 \mathrm{ml}$ were required).

The mixture was cooled to room temperature, filtered, concentrated to $25 \mathrm{ml}$ and again filtered. The filtrate was acidified to Congo red. After 15 minutes a colourless crystalline solid deposited, yield $25 \mathrm{mg}, \mathrm{m} . \mathrm{p}$. $146-151^{\circ}$. Vacuum sublimation raised the melting point to $151-152^{\circ} \mathrm{C}$. It analyzed as bromo-trimethoxybenzoic acid. (Found: C 41.5; $\mathrm{H} \mathrm{3.9;} \mathrm{Br} 27.6 ; 3 \mathrm{OCH}_{3}$ 32.2. Calc. for $\mathrm{C}_{10} \mathrm{H}_{11} \mathrm{O}_{5} \mathrm{Br}$ (291.1): C 41.3: $\mathrm{H} \mathrm{3.8;} \mathrm{Br} \mathrm{27.5;}$ $\left.3 \mathrm{OCH}_{3} 32.0\right)$. 
Its identity with 2-bromo-3,4,5-trimethoxybenzoic acid was proved by comparison of its ultraviolet absorption spectrum with that of a synthetic sample (Fig. 5).

Permanganate oxidation of bromopodophyllotoxin at $55^{\circ} \mathrm{C} .500$ milligrams of bromopodophyllotoxin were dissolved in $20 \mathrm{ml}$ of aceton. $11 \mathrm{ml} .4 \%$ potassium permanganate solution was slowly run in with continuous stirring at $55^{\circ} \mathrm{C}$. After heating for 30 minutes the colour had vanished, the aceton was distilled off, and the manganese dioxide was removed with sulphur dioxide gas. The solution was subsequently acidified to Congo red, extracted with chloroform, the combined chloroform extracts dried and evaporated to dryness in vacuo. The residue was dissolved in a mixture of $5 \mathrm{ml}$ of $99 \%$ ethanol and $5 \mathrm{ml}$ of benzene and chromatographed on $10 \mathrm{~g}$ of "Aluminiumoxyd neutral, Woelm", the same solvent mixture being used as an eluent. One eluate amounting to $50 \mathrm{ml}$ was collected. By evaporation of the solvents an almost colourless crystalline product (substence $19 / 10 / 54 / \mathrm{I}$ ) was obtained, yield $30 \mathrm{mg}$, m.p. $225-229^{\circ} \mathrm{C}$. It analyzed as bromopicropodophyllin (or bromopodophyllotoxin). (Found: C 53.9; H 4.2; $\mathrm{Br}$ (19.0); 3 $\mathrm{OCH}_{3}$ 19.3. Calc. for $\mathrm{C}_{22} \mathrm{H}_{21} \mathrm{O}_{8} \mathrm{Br}$ (493.3): C 53.5; $\mathrm{H} \mathrm{4.3;} \mathrm{Br} 16.2 ; 3$ OCH, 18.9).

3,4,5-Trimethoxybenzoic acid. The authentic specimen was prepared by methylation. of gallic acid according to. "Organic Syntheses"; m.p. $167^{\circ} \mathrm{C}$, lit. $167^{\circ} \mathrm{C}$.

2-Bromo-3,4,5-trimethoxybenzoic acid. $5.0 \mathrm{~g}$ of trimethoxybenzoic acid was dissolved in $40 \mathrm{ml}$ of chloroform. A solution of $3.8 \mathrm{~g}$ of bromine in $10 \mathrm{ml}$ of chloroform and some iron filings were added. The mixture was refluxed for 4 hours. The solvent was distilled off in vacuo and the residue was recrystallized from $400 \mathrm{ml}$ of water, active carbon being added for decolouration. Yield $4.0 \mathrm{~g}$ of colourless needles, m.p. $151-152^{\circ}$. $\operatorname{lit}^{12} 148^{\circ} \mathrm{C}$.

This work is part of investigations supported by Statens almindelige Videnskabsfond. Analyses are by Mr. W. Egger and Mr. P. Hansen, Chemical Laboratory, University of Copenhagen.

\section{REFERENCES.}

1. Dunstan, W. R. and Henry T. A. J. Chem. Soc. 73 (1898) 217.

2. Hartwell, J. L. and Schrecker, A. W. J. Am. Chem. Soc. 73 (1951) 2909; p. 2911.

3. Hartwell, J. L. and Detty, W. E. J. Am. Chem. Soc. 72 (1950) 246; p. 247.

4. Shriner, R. L. and Fuson, R. C. Identification of organic compounds New York 1948 , p. 93.

5. Kofod, H. and Jørgensen Chr. Acta Chem. Scand. 8 (1954) 1294.

6. Späth, E., Wessely F. and Kornfeld, L. Ber. 65 (1932) 1536; p. 1546.

7. Borsche, W. and Niemann, J. Ann. 499 (1932) 59; p. 62.

8. Späth, E., Wessely, F. and Nadler, E. Ber. 66 (1933) 125.

9. Späth, E., Wessely, F. and Nadler, E. Ber. 65 (1932) 1773.

10. Schrecker, A. W. and Hartwell, J. L. J. Am. Chem. Soc. 75 (1953) 5924.

11. Cook, J. W., Graham, W., Cohen, A., Lapsley, R. W. and Lawrence, C. A. J. Chem. Soc. 1944 322; p. 323.

12. Festschrift für Alexander Tschirsch, Loipzig 1926, p. 25.

13. Fround, M. Ann. 271 (1892) 311; p. 376.

14. Hershberg, Y., Lavie, D. and Bergmann, E. D. J. Chem. Soc. 19511030.

15. Kofod, H. and Jørgensen, Chr. Acta Chem. Scand. 8 (1954) 1296.

16. Kofod, H. and Jørgensen, Chr. Acta Chem. Scand. 8 (1954) 941.

17. Kofod, H. and Jørgensen, Chr. Acta Chem. Scand. 9 (1955) 347.

18. Gensler, W. J. Private communication.

Received May 13, 1955. 